Acta Crystallographica Section B

Structural

Science

ISSN 0108-7681

\section{addenda and errata}

\title{
$\left[\mathrm{Ru}(\mathrm{py})_{4} \mathrm{Cl}(\mathrm{NO})\right]\left(\mathrm{PF}_{6}\right)_{2} \cdot 0.5 \mathrm{H}_{2} \mathrm{O}:$ a model system for structural determination and ab initio calculations of photo-induced linkage NO isomers. Erratum
}

\author{
Benoît Cormary, ${ }^{\mathrm{a}, \mathrm{b}}$ Isabelle Malfant, ${ }^{\mathrm{a}, \mathrm{b} *}$ Lydie Valade, $^{\mathrm{a}}$ \\ Marylise Buron-Le Cointe, ${ }^{c}$ Loïc Toupet, ${ }^{c}$ Teodora \\ Todorova, ${ }^{\mathrm{c}}$ Bernard Delley, ${ }^{\mathrm{d}}$ Dominik Schaniel, ${ }^{\mathrm{e}}$ Nicholas \\ Mockus, ${ }^{e}$ Theo Woike, ${ }^{e} *$ Karla Fejfarová, ${ }^{f}$ Václav Petříček ${ }^{\mathrm{f}}$ \\ and Michal Dušek ${ }^{\mathfrak{f}}$
}

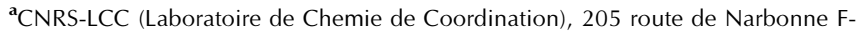
31077 Toulouse, France, buniversité de Toulouse, UPS, INPT, LCC, F-31077

Toulouse, France, 'Institut de Physique de Rennes, UMR UR1-CNRS 6251,

Université de Rennes 1, 35042 Rennes, France, ${ }^{\mathbf{d} C}$ Condensed Matter Theory, Paul Scherrer Institut, 5232 Villigen PSI, Switzerland, ${ }^{\mathbf{e}}$ Physikalisches Institut, Universität zu Köln, Zülpicher Strasse 77, 50937 Köln, Germany, and ' Institute of Physics,

Acadmy of Sciences of the Czech Republic, Na Slovance 2, 18221 Praha 8, Czech

Republic

Correspondence e-mail: isabelle.malfant@lcc-toulouse.fr, th.woike@uni-koeln.de

In the paper by Cormary et al. [Acta Cryst. (2009), B65, 612$623]$ two authors were inadvertently omitted from the author list and one name was given incorrectly.

In the paper by Cormary et al. [Acta Cryst. (2009), B65, 612-623] two authors were inadvertently omitted from the author list. The missing authors are Lydie Valade and Teodora Todorova. Also, the name of one of the authors was given incorrectly. The correct name should be Marylise Buron-Le Cointe. The complete list of authors is given above.

\section{References}

Cormary, B., Malfant, I., Buron-Le Cointe, M., Toupet, L., Delley, B., Schaniel, D., Mockus, N., Woike, T., Fejfarová, K., Petř́íček, V. \& Dušek, M. (2009). Acta Cryst. B65, 612-623. 